A. Q. Wells, Dr. Carmichael, Dr. Conalty and Mr. W. Freeman. Prof. F. S. Stewart presided.

In the fourth session, the chair was occupied by Prof. T. G. Moorhead. Dr. George Brownlee opened the proceedings with a talk on the present status of antibiotics in tuberculosis. This was a stimulating and original contribution, which characteristically had little relevance to the title. Dr. Brownlee described six biochemical lesions which follow invasion by a tubercle bacillus : multiplication of the parasite, chemiotaxis of monocytes, inhibition of proteases, hypersensitivity effect, skin allergy and acquired resistance. Specific antimicrobial chemotherapy is associated only with the first. Three factors influence the effect of chemotherapeutic agents on a bacterial population : the efficiency of the agent, the effect of the number of the organisms, and the rate of emergence of resistant strains. Dr. Brownlee dealt at length with the role of hypersensitivity in the spread of the disease. He visualized the advent of an anti-anaphylactic drug which will effectively modify tuberculin hypersensitivity. This may be expected to revolutionize our present-day concepts of the limitations of conventional chemotherapy of tuberculosis. $\mathrm{H}_{\theta}$ also expressed the opinion that the evidence appears to be complete that a chemical entity exists in suitably prepared dead tuberclo bacilli, which is antigenic and protective. Though this substance may be labile in character, he believed that ways will be found of extracting it. Opening the discussion, Dr. D. G. Madigan described the treatment of a group of patients with bacillary emulsion under the cover of effective chemotherapy with streptomycin and $p$-aminosalicylic acid. In 50 per cent of patients, it is possible to achieve desensitization as measured by the skin test (to 1 in 10) in six weeks. Dr. P. Swift described the treatment of tuberculous meningitis with streptomycin. In his opinion it is not now justifiable to use streptomycin by itself. The remainder of the session was devoted to a lively discussion on the origin and nature of streptomycin resistance, in which Prof. Kennedy, Dr. D. A. Mitchison, Mr. G. W. Dawson, Dr. J. Crofton and Prof. Julius took part.

The second half of the colloquium opened in Trinity College with Dr. Gerhard Domagk's lecture, Prof. W. R. Fearon presiding. Prof. Domagk said that three compounds have been used in the treatment of chronic tuberculosis infection : the thiosemicarbazones (conteben), streptomycin and $p$-aminosalicylic acid. All three are active against different types of tubercle bacilli both in vitro and in vivo. In the experimental animal, a combination of conteben and streptomycin has proved more effective than streptomycin alone or any other combination. Side reactions at first attributed to the thiosemicarbazone itself are to some extent due to dead or damaged bacilli. It is possible to obtain extensive fatty degeneration of the liver by injection of dead bacilli only. The thiosemicarbazones are being used extensively in South America and Central Africa for the treatment of leprosy. In the discussion, Dr. A. R. Martin pointed out that $T B$ III ( $p$-ethylsulphonylbenzaldehyde thiosemicarbazone) is better tolerated in man than conteben and produces much higher blood-levels with equal dosage. Dr. Barnes described a trial which he has conducted with a series of cases of tuberculoid and lepromatous leprosy. Conteben was effective in the former type, but very much less effective with the latter. In reply to Mr. Francis, whose experience has been that none of the partially successful tuberculosis and leprosy drugs have any appreciable effect on rat leprosy, Dr. Domagk pointed out that the strain of leprosy bacillus infecting man is quite different from the rat leprosy bacillus. It also emerged from the discussion that there is little information available as to the effect of thiosemicarbazones on streptomycin-resistant strains of tubercle bacilli.

The sixth and seventh lectures were mainly of interest to clinicians. Dr. Marc Daniels spoke on "The Clinical Evaluation of Potential Chemotherapeutic Agents in Pulmonary Tuberculosis". $\mathrm{He}$ described the various rigorous procedures and teamwork which alone can make a clinical trial of a new drug of value. Prof. J. M. O'Connor presided.

At the final session, Prof. J. McGrath presiding, Mr. J. T. D. Lane described his experience in the treatment of a number of cases of renal tuberculosis with streptomycin and a smaller number with B.283. The latter cases had failed to respond to strepto mycin. It was clear that both drugs are more effective when dealing with early lesions. He thought. it likely that a combination of the two drugs may prove more effective than either alone. In vesical tuberculosis persisting after nephrectomy, B.53. appears to be very effective. In this type of case, in his experience, streptomycin is only effective when the lesions are superficial.

It was a highly successful and lively conference, owing much of its success to the presence of workers interested in every stage of the chemotherapy of the disease, to the logical arrangement of the programme and finally to the fact that the limited number of contributions did not produce the mental indigestion frequently associated with gatherings of this kind. 'The chemists' contributions were tinged somewhat with melancholy, but not completely despairing. The biologists were optimistic and fruitful in theories. The bacteriologists among them appeared to be quietly confident that their routine procedures were adequate to any demands that might be made on them. The clinicians, however, as instanced by Dr. E. T. Freeman, were polite but firm in pointing out that the desired chemotherapeutic agent for tuberculosis has yet to be discovered.

A complete record of the proceedings will be published later this year as a special issue of the Irish Journal of Medical Science. VINCENT C. BARRY

\section{THE FAWLEY REFINERY}

$F^{\circ}$ OR the past two years, ever since the first grader started site-clearance in July 1949, the word 'Fawley' has taken on a new meaning in British oil circles. The place itself was of small consequence on a comparatively little-known peninsula between Beaulieu River and Southampton Water, save for the existence of the original Esso Petroleum Company's oil refinery, in operation for some thirty years past. All this has now changed. The new Esso refinery, officially opened by the Prime Minister on September 14, is an accomplished fact, a triumph of American and British brains and skill, a monument to the close ties binding the two countries in peace as well as in war.

The history of this outstanding example of initiative and enterprise is as impressive as is the vista of the whole complex plant itself. Begun in 1949, it was 
actually completed this year four months ahead of schedule. The scheme involved clearing and levelling 450 acres of wooded gravel-land; construction of roads; laying down a railway system to connect up with permanent way to Southampton; erecting a huge building, $800 \mathrm{ft}$. long, $180 \mathrm{ft}$. wide and occupying more than 3 acres, first to house constructional materials, ultimately to serve as maintenance and machine shop; lay-out of a construction camp on site for 750 workmen; erection of a huge concrete plant with output of 140 cubic yards per hour, one of the largest in the world ; installation of the main refinery units, in itself a colossal task of erecting and linking-up the bewildering maze of pipes, tanks, stills, furnaces and huge towers that go to make up a modern oil refinery. Add to this permanent houses for key-staff, a beautiful theatre and games building (social club) and it is at once obvious that the Fawley we used to know has been completely transformed into a self-contained city of potentially some 2,000 inhabitants ; incidentally, some of the original inhabitants appeared to be almost Americanized.

A tour of the refinery during the day before the official opening provided unrivalled opportunity for studying the lay-out in technical detail. Crude oil is delivered by tanker to a specially constructed marine terminal, a 3,200-ft. jetty jutting into Southampton Water and connected to the main plant by a 2,000-ft. long approach road, constructed over salt marshland, carrying oil, steam and salt-water pipe-lines into the heart of the refinery itself. Thence fed to storage tanks, oil eventually passes through pipe-still furnaces to heat it up to $750^{\circ} \mathrm{F}$.; thus vaporized, it enters the fractionating tower where condensation takes place at different levels on 'bubble trays'.

There are three fractionating towers here, two operating at atmospheric pressure, and a third under vacuum with steam distillation to deal with 'bottoms' from the other two. An outstanding feature is undoubtedly the huge catalytic cracking plant ("cat cracker') fed with gas oil, using a catalyst in an extremely fine state of particle division (technically known as 'fluid catalytic cracking'). A specially designed thermal-cracking plant converts lubricating oil and motor spirit into high-octane spirit plus gas. A polymerization plant determines increase in octanerating of motor spirit obtained by distillation. A debutanizer tower, $113 \mathrm{ft}$. high, weighing 135 tons, separates butane and associated volatiles from motor spirit, designed to meet current vapour-pressure specifications. The copper sweetening unit removes corrosive compounds and evil-smelling vapours from motor spirit. Then there is the Edeleanu plant for improving burning qualities of kerosene; a hypochlorite plant for removing unpleasant sulphur compounds from kerosene and turbo-jet fuels; the lubricating oil plant, involving propane de-asphalting, phenol extraction, propane de-waxing and clay treatment processes. The oxidizing plant produces some well-known 'blown' grades of asphaltic bitumen; a 'specialty' unit manufactures anti-corrosive additives for lubricating oil ; a hydro-desulphurization plant effects removal of sulphur from tractor-fuel.

In view of the serious shortage of sulphur at the present time, a vitally important unit under construction is the sulphur plant, for the conversion of hydrogen sulphide, released during varying stages of refining crude oil, into chemically pure 99.5 per cent rock sulphur. Full sulphur production is scheduled for early 1953; output will be of the order of 12,000 tons a year.
Fawley now assumes priority as the largest oil refinery in Europe. It cost $£ 37,500,000$ to build. When in full operation it will produce $6,500,000$ tons of petroleum products a year ; more than a million gallons of motor spirit a day; and nearly 30 per cent of present total demand for petroleum and products in the British Isles. Not least in these financially stringent times, this brilliantly planned and executed work will-effect a saving in foreign exchange of more than 2 million dollars a week.

Someone concerned with the lavish series of publications which a great occasion like this official opening obviously presented had the foresight and sensitive imagination to commission $H$. E. Bates to write a commemoration "Fawley Achievement", "as a tribute to the vision, skill, and energy of all those who helped to plan and build it". Much praise was heard throughout the time of our tour of the new Fawley; but many read this tribute with a feeling that no one could have done it better than Bates, nor given to the sponsors of this great enterprise more encouragement for the future than is justly their due.

H. B. MILNER

\section{OBITUARIES}

\section{Mr. G. Udny Yule, C.B.E., F.R.S.}

George UDNY YULE was a member of a family distinguished for its scholarship and administrative talent. His father, Sir George Udny Yule, a very successful administrator in the Indian Civil Service, was one of three sons of Major William Yule, of the East India Company's service, who was born in 1764 and was in his day a well-known Orientalist; of the others, one, Lt.-Colonel Robert Abercromby Yule, a rising cavalry officer, was killed at Delhi in command of the 9 th Lancers in 1857 ; the other, Colonel Sir Henry Yule, is remembered internationally for his authoritative edition of Marco Polo's travels. Udny Yule thus had an oral tradition of learning and of civil and military administration reaching back to the end of the eighteenth century. Udny Yule himself was educated at Winchester and University College, London. Science and engineering were his early interests, and he spent a postgraduate year under Hertz at Bonn on research into the passage of electric waves through dielectrics, which formed the subject of his first published paper. This field, however, was not very close to his heart, and he never reverted to it.

Udny Yule's scientific career proper began in 1893, when he joined Karl Pearson at University College, London, as lecturer in statistics. Pearson was laying the foundations of the science of theoretical statistics and it was not long before Yule himself was making fundamental contributions to the subject. For the next fifteen years he devoted himself mainly to the theory of statistical relationship, publishing basic memoirs on correlation $(1897,1907)$ and on association (1900). His work on association was later (1912) summarized in a further paper, and little has been added to it since; his work on correlation, in one form or another, continued throughout most of his life.

From 1902 onwards Yule gave a series of Newmarch Lectures which in 1911 were amplified and published as "An Introduction to the Theory of Statistics". This famous text-book remained for many years the only extensive account of the subject. There are very few students of statistics even to-day 